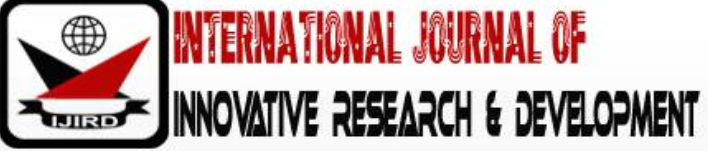

ISSN 2278 - 0211 (Online)

\section{Food Security Dynamics, Transition and Dimension: Evidence from Rural Households in Nigeria}

Jerumeh Elijah Gift
Ph.D. Candidate, Department. of Agricultural Economics, University of Ibadan, Nigeria
Jerumeh Tolulope Rachael
Student, Department of Agricultural Economics, University of Ibadan, Nigeria
Salman Kabir Kayode
Senior Lecturer, Dept. of Agricultural Economics, University of Ibadan, Nigeria

\begin{abstract}
:
The study investigates the dynamics of food security transitions among rural households in Nigeria. Secondary data from Generalised Household survey (GHS), a country-wide panel data conducted in 2010/2011, 2012/2013 and $2015 / 2016$, were employed in the study. Out of the 5,000 households covered by the survey, the study only used 1,829 households whose characteristics were found relevant to the realization of the objectives of the study. Findings showed that although majority of the household heads were food secure in 2010 and 2012, almost one half of this population transitioned into food insecurity in 2015. Sex of the household head, marital status and asset ownership were identified as key determinants of mobility into food insecurity. In the long run, the probability that a household in rural Nigeria will transition into food security is $62.2 \%$ while the probability of exiting the status is $38.27 \%$.The study also revealed that the relatively high and fairly stable level of food security in the sampled area can be linked to socio-demographic factors such as household size, marital status, years of education, asset ownership, access to credit or extension and nonfarm income. Since exiting food security status remains a challenge in rural areas, interventions targeted at increasing literacy level, access to credit as well as providing other such safety nets should be encouraged.
\end{abstract}

Kevwords: Food securitv, determinants, panel data, transition, rural households

\section{Introduction}

Studies on food security are particularly important as food security has been shown to be greatly linked with the economic development of any nation. Without a country owned and country-driven food security strategy, there will be obstacles and additional costs to global, regional and country level economic growth (Torero, 2014).Food security, as defined by the United Nations' Committee on World Food Security, is the condition in which all people, at all times, have physical, social and economic access to sufficient safe and nutritious food that meets their dietary needs and food preferences for an active and health life (CFS, 2012). Attaining this level of food security requires the availability of food supply, adequate access to food supply, appropriate utilization of food and stability of food supply (Gross et al., 1998).

Despite the acclaimed role of food security in economic growth and stability, food insecurity still remains an issue of global concern. For example, according to an FAO report, about 805 million people in the globe arechronically undernourished in between the years 2012-14, of which an estimated 791 million chronically hungry people were from developing countries (Gazuma, 2018). This situation is more evident in Asia and Africa where more than 92\% of the world's undernourished people are living - 552 and 226.4 million respectively (Abdullah et al, 2017). Sub-Saharan Africa has become home to more than a quarter of the worlds' undernourished people, owing to around one in four people in the region remains undernourished (Gazuma,2018).As is the case with many developing countries, Nigeria is one of the hardest hit countries by high levels of malnutrition, poverty and diseases. Nigeria, for example has been ranked 91st out of a total of 104 countries on the 2015 Global Hunger Index and 153rd out of a total of 187countries on the 2012 UNDP Human Development Index with about 60\% of her population living on less than US\$1.25 per day (WDI,2015). These statistics are disconcerting given the country's abundant natural and human resources of the country.

Other dimensions of food insecurity can be viewed in terms of the prevalence of stunting, wasting and mortality rates among under-five children and the corresponding statistics for Nigeria were obtained from World Bank (2016). The prevalence of wasting in children under 5 years and the proportion of the undernourished were 6.7 and 19.8 \%respectively in 2014. Also, under 5 mortality rate (per 1000 live births) and the prevalence of stunting in children, though practically decreasing over the years, are still very high (32.9\% and 112.5 respectively in 2014).The disturbing state of malnutrition in sub-Saharan region has been shown to be increasingly associated with economic and human costs(USAID, 2014). The economic costs are so large and are evident in the 90 percent reduction of Gross Domestic 
Product (GDP) totals of Africa and Asia which wouldn't have been in the absence of under nutrition. The human costs have been identified in terms of high rate of avoidable mortality and morbidity.

It should however be noted that growing population coupled with increased intensity of environmental extreme events i.e.floods, droughts, extreme variability in temperature and rainfall has increased the pressure on current food production systems and has threatened the current food security in most of thedeveloping countries (GOP, 2014).For instance, the annual urban growth rate (2.3\% from 2000-2004) in sub-Sahara Africa has been more rapid than in other part of the world (Junge et al., 2006). The goal of attaining food security in these countries has also been fraught with the neglect of agriculture relevant to very poor people by governments and international agencies, the current worldwide economic crisis, and the significant increase of food prices (FAO, 2010; 2011a)

From the foregoing, achieving food security depends largely on three key dimensions- food availability, access and utilization. With varying levels of foreign exchange reserves, and huge dependence on food imports apparent in many developing countries, especially Nigeria, there is an overarching need to ensure food self-sufficiency through increased domestic food production. This can be achieved through effective and continuous supply of food, especially in an agriculture-based country like Nigeria, where food production is largely rain-fed and subject to wide variations due to weather vagaries. Since the bulk of agricultural labour force in Nigeria comes from the rural areas, there is a need for a study which will investigate the food security status of rural dwellers as this has been shown to be greatly linked to productivity. Food insecurity disproportionately affects rural people particularly rural women, minorities and children (London et $\mathrm{al}, 2005$ ) and this has been connected to poverty, income inadequacies, limited access to resources, underemployment, and unemployment among others (World Bank 2001; London et al, 2005). Essentially, this study will conduct a detailed analysis of food security dynamics and transition, the outcome of which is critical to the formulation of appropriate and effective policies to address the problem of food security in Nigeria. Therefore, the main objective of this study is to investigate the main drivers of transitions in food security status of rural households in Nigeria.

\section{Theoretical Consideration: An Overview of the Estimation Methods for Panel Data}

Panel data refers to data sets consisting of multiple observations on each sampling unit which may be generated by pooling time-series observations across a variety of cross-sectional units such as countries, states, regions, firms, or randomly sampled individuals or households (Baltagi undated). The combination of time series with cross-section can enhance the quality and quantity of data in ways that would be impossible using only one of these two dimensions (Gujarati, 2003). However, the analysis of panel data requires more complex statistical models, which often times are difficult to estimate, than those used for time-series or cross-sectional data. This is because models for panel data must accommodate the fact that observations for the same unit over time are unlikely to be independent of one another (ESRC, 2006)

Based on its applicability in different fields, quite a number of models exist for analysing panel data. The paper however describes five general approaches to the estimation of panel data: Pooled regression, Random parameters, fixed effects (FE) and random effects (ME) model. The pooled regression model, also called the constant coefficients model, is a panel model that has constant coefficient for the slope vector and intercept (Greene, 2010). In an event where there is neither significant country nor significant temporal effects, the data can be pooled and analysed using ordinary least squares regression model (15) which provides the consistent and efficient estimates of the intercept and the slope. In Random parameter models, the constant term and the slope are allowed to change across the cross-sectional units. The model in this form can be given as (Greene,2010):

$$
Y_{i t}=x_{i t}^{\prime}\left(\beta+g_{i}\right)+\left(\alpha+u_{i}\right)+\varepsilon_{i t} i-1,2, \ldots, n \text { and } t=1, \ldots, T
$$

Where $Y$ is the observed outcome, $\beta$ is slope vector, $\alpha$ is the constant term and $\mathrm{x}$ is the time variant and invariant vector strictly of exogenous attribute, $u_{i}$ is a group-specific random element, $\varepsilon_{i t}$ is the random error that varies from wave to wave for each cross-sectional unit and $h_{i}$ random vector that induces changes of the parameters across the units. This model assumes neither heteroskedasticity nor autocorrelation within the panels to avoid complicating the covariance matrix.

The two other popular methods of estimating panel data are FE and RE models. Both FE and RE differs in their assumption about the relationship between the observed and unobserved predictors. A fixed effects model results if $Z_{i}$ (unobserved individual heterogeneity) is correlated with the observed variables ( $\mathrm{x}_{\mathrm{it}}$ ) (Greene, 2010). In essence, FE models "subtract" off" bothobserved and unobserved time-constant factors using the panel structure of the data (Vaisey and Miles, 2014). In this instance, the model is given as (Green, 2010)

$$
Y_{i t}=x_{i t}^{\prime} \beta+\alpha_{i}+\varepsilon_{i t}
$$

Where $\alpha_{i}=Z_{i}^{\prime} \alpha$ represents all observable effects with estimable conditional mean.

Random effects model on the other hand assumes that the measured variables in the model are uncorrelated with $\mathrm{Z}_{\mathrm{i}}$. The random effects model is a random constant term (Greene, 2003) which is a function of a mean value and a random error.

$$
\begin{aligned}
Y_{i t}=x_{i t}^{\prime} \beta & +E\left[Z_{i}^{\prime} \alpha\right]+\left\{Z_{i}^{\prime} \alpha+E\left[Z_{i}^{\prime} \alpha\right]\right\}+\varepsilon_{i t} \\
& =x_{i t}^{\prime} \beta+\alpha+u_{i}+\varepsilon_{i t}
\end{aligned}
$$


The random effect approach specifies that ui is a group-specific random element, similar to eit except that for each group, there is but a single draw that enters the regression identically in each period.

In principle, none of these models is considered to be out-and-out superior to others but rather the decision on which approach is to be employed depends, to a reasonable extent, on the type of data available and the objective(s) the research intends to achieve. However, RE and FE models, more especially FE models, are powerful and underused method that leverages the power of panel data to provide protection against unobserved heterogeneity, though they don't serve as a panacea (Vaisey and Miles, 2014). In extension, the confidence placed in the coefficient estimates must rely on theoretical justification and the degree to which the data is representative of the real-world situation.

\section{Methodology}

The paper examined food security status of rural households in Nigeria using the Generalised Household Survey (GHS) which is a country-wide panel data collected by the National Bureau of Statistics (NBS) in collaboration with the team from World Bank Living Standards Measurement Study (LSMS). This collaboration forms part of the Integrated Surveys on Agriculture (ISA) programme and was recently reviewed to include GHS-panel representing the panel component of the survey. The GHS-Panel is a nationally representative survey covering about 5,000 households and were collected in 2010/2011, 2012/ 2013 and 2015/2016. More importantly, GHS-Panel is the only panel data centred on agricultural households in Nigeria. Data extracted from the three waves of the survey include socioeconomic characteristics, household food consumption expenditure, asset ownership, access to credit or extension services among others. In the final analysis, 1829 households whose characteristics the study finds relevant to the achievement of its objectives and available in all the three waves were used.

\section{Method of Data Analysis}

The analytical methods employed in the study include descriptive statistics (mean, Frequency distributions, percentages, measures of central tendencies, Charts etc.), Markov chain analysis and fixed effects Probit model.

\subsection{Estimating Food Security Index}

A number of methods exist for measuring the food security status of households. These include the calorie intake method (Ahmed et al, 2017),Food energy Intake (Ayantoye et al (2011) and food sufficiency (Nyyssola et al,2012), Dietary Intake Assessment (Ahmed et al, 2017) and food expenditure approach (Ayantoye et al, 2011). The study employed the food expenditure method because of its wide acceptance and ease of computation.

Food security index, as adapted from Omonona and Agoi (2007), can be expressed as

$F_{i}=\frac{P F E_{i}}{2 / 3^{M F E}}$

Where $F_{i}$ is Food security index of the ith household

PFE is the monthly per capital food expenditure of the ith household

MFE is the mean monthly per capita food expenditure of all the households

And $i=1,2,3, \ldots, 1829$

Based on the above calculation, households were classified into food secure and food insecure. Food secure if $F_{i} \geq 1$, and Food insecure if $F_{i}<1$

In other words, household is said to be food secure if its food security index is equal to or greater than two-third of the total households' mean monthly per capita food expenditure $\left(F_{i} \geq M P E\right)$ while a food insecure household is one whose food security index is less than the mean monthly per capita food expenditure of the total sample $\left(F_{i}<M P E\right)$

\subsection{Markhov Chain Analysis}

The study employed Markhov chain analysis to provide an understanding of how households transit within food security categories during the three survey periods (2010/2011, 2012/2013, 2015/2016). The transition matrix provides,at first glance, the number of households entering or exiting food security. As further adapted from Amao and Ayantoye (2015), a Markhov chain limited to first order homogenous Markhov chain is given in Table 1.

\begin{tabular}{|c|c|c|c|}
\hline Period (t) & \multicolumn{3}{|c|}{ Period (t+1)/(t+2) } \\
\hline & Food Secure & Food Insecure & Total \\
\hline Food Secure & $n_{11}$ & $n_{12}$ & $R_{1}$ \\
\hline Food insecure & $n_{21}$ & $n_{22}$ & $R_{2}$ \\
\hline Total & $C_{1}$ & $C_{2}$ & \\
\hline
\end{tabular}

Table 1: First-Order Markhov Model for Food Security Transitions

Source: Modified from Amao and Ayantoye (2015)

From Table 1, $n_{11}$ to $n_{22}$ represents the number of households in each category while $C_{1}$ and $R_{1}$ are column and row totals respectively. For example, $n_{11}$ represents the number of households who remained food secure in the two time periods being considered. It should however be noted that who remained in a given category over a given period of time are said to be in a stationary state $\left(n_{11}\right.$ and $\left.n_{22}\right)$ while those who entered or exited a given category are considered to be in translational state $\left(n_{21}\right.$ and $\left.n_{12}\right)$. To obtain the probability of moving into or exiting a given category, the transition matrix is converted to a probability matrix by dividing each observation in the transition matrix by its matching row total. The resulting probability matrix is as shown below: 


$$
\left[\begin{array}{ll}
P_{11} & P_{12} \\
P_{21} & P_{22}
\end{array}\right]
$$

To determine the number of households that will be within a given food security category during the three periods of survey considered in the study, a probability equation as given by Baulch and McCulloch (1998) was used.

$$
P_{(t)}=P_{0} P_{i j}^{t}
$$

Where $\mathrm{t}$ is the time period, $P_{0}$ is the vector of initial probability and $P_{i j}$ is the probability of rural households moving into or exiting food security. The long run equilibrium, which is attained when the number of people entering into food security equals those that are exiting, is expressed as:

$$
u P=u
$$

This can be explicitly expressed as:

$$
\left(U_{1} U_{2}\right)\left[\begin{array}{ll}
P_{11} & P_{12} \\
P_{21} & P_{22}
\end{array}\right]=U
$$

Solving the above matrix gives the values of $U_{1}$ and $U_{2}$ which implies the proportion of rural households in Nigeria that will be food secure or food insecure in the long run. Specifically, at equilibrium, $\mathrm{U}_{1}$ represents the households that will be food secure in the long run while $U_{2}$ is the long run forecast of households who will become food insecure.

\section{Random Effects Probit Model}

The Random effects probit regression model was used to identify the determinants of the different transitions in the food security status of rural households in Nigeria. The study employed the random effects probit model because there is no command for the conditional fixed-effects model due to insufficient statistics to condition the fixed effects from the likelihood and thus and the use of such produce bias results (StataCorp,2015). Also, since fixed effect model deals with variation in outcome within individuals, fixed effects logit model, which would have been an alternative model, could not be used as the data employed by the study have quite a large number of individuals whose characteristics did not change appreciably over the three periods. These realizations further strengthened the need to use random effects probit model in our analysis.

The Random Effects probit model is generally used to estimate trend in binary variable measured repeatedly in the same subjects (Gibbons and Bock, 1987). The model finds its application in cases where the dependent variable is specified as a sequence of correlated binary responses. These binary responses can be a product of longitudinal (individuals) or cluster (individual within groups) response process. In the specification of the model, a restriction that the correlation between successive error terms for the same individual is a constant is imposed. In addition, the model provides maximum likelihood estimates for time-varying and time-invariant covariates in the longitudinal case and covariates which vary at the level of the individual and at the cluster level for multilevel problems. The Random effects regression modelis presented as follows (Arulampalam 1996):

Given the following model,

$$
\begin{array}{r}
Y_{i t}^{*}=x_{i t}^{\prime} \beta+\alpha_{i t} \quad i-1,2, \ldots, n \text { and } t=1, \ldots, T \\
\quad \alpha_{i t}=\mu_{i t}+\delta_{i t}
\end{array}
$$

and

$$
Y_{i t}=1 \quad \text { if } Y_{i t}^{*}>0 \text { and }=0 \text { if otherwise }
$$

Where $\mathrm{Y}^{*}$ represents the unobservable variable, $\mathrm{y}$ is the observed outcome, $\beta$ is the vector of explanatory variables, $\mathrm{x}$ is the time variant and invariant vector strictly of exogenous attributes, $\mu$ and $\delta$ are the individual specific unobservable effects and random error respectively

Assuming a normal distribution that $\delta_{i t} \sim \operatorname{IN}\left(0, \delta_{u}^{2}\right)$ and conditional on $x_{i t}, \mu_{i} s$ are $\left(0, \delta_{u}^{2}\right)$ and independent of $\delta_{i t}$, the random probit model is given as (Heckman, 1991):

$$
\left(\operatorname{Prob}\left(Y_{i t}=1 \mid \mu_{i}, x_{i t}\right)=\left(\frac{\delta_{i t}}{\sigma_{u}}>\frac{-x_{i t}^{\prime} \beta-\mu_{i}}{\sigma_{u}}\right)=\left(\quad\left(Z_{i t}\right)\right.\right.
$$

Where

$$
Z_{i t}=\frac{-\left(x_{i t}^{\prime} \beta+\mu_{i}\right)}{\sigma_{u}}
$$


and represents the distribution function of the standard normal variate.

Marginalising the appropriate likelihood function with respect to $\mu$ gives,

$\prod_{i}\left\{\int_{-\infty}^{\infty} \prod_{t=1}^{T}\left[1-\left(x_{i t}^{\prime} \beta^{*}+\sqrt{\frac{\omega}{1-\omega}} \mu^{*}\right)\right]^{1-Y_{i t}}\left[\left(x_{i t}^{\prime} \beta^{*}+\sqrt{\frac{\omega}{1-\omega}} \mu^{*}\right)\right]^{Y_{i t}}\left(\mu^{*}\right) d \mu^{*}\right\}$

where $\beta^{*}=\beta / \sigma_{u}$ and $\mu^{*}=\mu / \sigma_{u}$.

Based on the above equations, the study used a simplified representation of the random effects probit model as follows:

$$
\begin{gathered}
F s_{i j}=\beta_{i j}+\beta_{1} S E X+\beta_{2} A G E_{i j}+\beta_{3} M A R_{i j}+\beta_{4} H S I Z_{i j}+\beta_{5} Y E D U_{i j}+\beta_{6} A S S E T_{i j}+\beta_{7} C R E D_{i j}+\beta_{8} N O N F M_{i j}+\beta_{9} L A N D_{i j} \\
++\beta_{10} E X T_{i j}+\beta_{11} L A N D_{i j}+\beta_{12} E X T_{i}+\delta_{i j}+\alpha_{i j}
\end{gathered}
$$

here

$\beta_{i s}$ are the parameters to be estimated, $\mathrm{i}=1,2, \ldots, 1829$ (the cross-sectional units), $\mathrm{j}$ is equal to1, 2,3 or 4 representing the food security transition groups, $\delta$ and $\alpha$ are between- error and within- error terms, respectively. FS is the probability of being food secure ( $F S=1$ if food secure and 0 if otherwise). Nine explanatory variables, whose selections were based on data availability, theoretical considerations and literature review, were considered in the study (Eqn 10). These variables, with reference to the household head, are $S E X=s e x(D=1$ if male, 0 if otherwise), AGE=age (years), MAR= marital status ( $D=1$ if married, 0 if otherwise), HSIZ=household size (no.), YEDU=years of education, $C R E D=$ access to credit ( 1 if yes, 0 if otherwise), ASST = asset ownership (no owned), FAMZ= farm size (ha)), ANIM-animal holding (no.), NOFM=non-farm income ( $1=y e s, 0$ if otherwise) and EXT=access to extension service ( $D=1$ if yes, 0 if otherwise).

To examine the determinants of these various food security transitions, the study employed a probit model specified as:

$P_{i j}=\beta_{0}+\beta_{1} S E X_{i 10}+\beta_{2} A G E_{i 10}+\beta_{3} M A R_{i 10}+\beta_{4} H S I Z_{i 10}+\beta_{5} Y E D U_{i 10}+\beta_{6} A_{S S E T_{i 10}}+\beta_{7} C R E D_{i 10}+\beta_{8} N O N F M+$

$\beta_{9} L A N D_{i 10}++\beta_{10} E X T_{i 10}++\varepsilon_{i 10}$

For the dependent variable in equation 11 , the study modelled four food security pathways as follows:

- Exiters $\left(P_{i 1}\right)$ : those who were formerly food secure in 2010 or 2012 but moved out from the category in 2012 or 2015

- Entrants $\left(P_{i 2}\right)$ : those who were previously food insecure in 2010 or 2012 but later became and remained food secure

- Chronic food insecure $\left(P_{i 3}\right)$ : are those who were food secure in all the three years

- Always food secure $\left(P_{i 4}\right)$ : refers to those who remained food insecure in all the years

As shown above, $P_{i j}$ represents the probability of being in the pathways specified above (e.g. being always food secure or otherwise), the explanatory variables are as specified in equation 10 and $\varepsilon$ is the residual error term. Following Pitoro and Chagomoka (2017), 2010 ( 10 subscript)values of the explanatory variable were used in the probit model since the aim of the study is to know the extent to which initialhouseholds' endowments contribute to food security over time. Finally, in the calculation of the short and long run equilibriums, the study used 2010 and 2015 as the reference years.

\section{Results and Discussion}

\subsection{Socioeconomic and Demographic Characteristics of Rural Households}

Table 1 shows population-weighted summary statistics of selected key variables in the three waves considered in the study (2010/11.2012/ 13 and 2015/2016). The distribution of the household heads shows that great majority of the rural households are headed by males and this was found to be consistent in all the waves (93.5\%). As expected, the mean age of the household heads increased from $47.9 \pm 0.32$ years in wave 1 through $50.5 \pm 0.32$ years in wave 2 to $53.0 \pm 0.32$ years in wave 3. Although the household heads are aging, the mean age indicates that majority of the household heads are still in their active years and are more likely to be involved in productive and economic activities which will help assuage the problem of food insecurity. Results from Table 4 also shows that a larger percentage of the household heads were married (approximately 92\% in all the waves) with about 8-9 years of formal education. The average household size was observed to increase arithmetically across the waves from $6.7 \pm 0.07$ years in the first wave to $8.1 \pm 0.08$ in the third wave.

Although the percentage of household heads who owned their farm land followed no definite pattern, farm size was found to decrease across the waves $(3.6 \pm 0.7$ ha, $2.1 \pm 0.2$ ha and $1.9 \pm 0.3$ ha in wave 1 , wave 2 and wave 3 respectively). The reason for this decline could be due to the need to generate additional income from non-farm activities as participation in these activities increased from $50.7 \%$ to $61.1 \%$ while farm size decreased by almost half between wave 1 and wave 2. Households' monthly food expenditure was observed to increase across the waves (\$3277.4, $\$ 3610.5$ and N800.9 in wave 1, wave 2 and wave 3 respectively) and by implication, food security status is expected to increase over the years. Across the waves, the standard errors were observed to be essentially unchanged except in monthly food expenditure where the change was minimal (64.0 to 71.10). From this result, it can be inferred that it is either the distributions of the variables of interest have remained more or less unchanged or there haven't been significant changes in the quality of data across the three waves. 


\begin{tabular}{|c|c|c|c|c|c|c|}
\hline Characteristics & \multicolumn{2}{|c|}{ Wave1 (A) } & \multicolumn{2}{c|}{ Wave2 (B) } & \multicolumn{2}{c|}{ Wave 3 (C) } \\
\hline & Mean & S.E & Mean & S.E. & Mean & S.E. \\
\hline Age of HH & 47.94 & 0.324 & 50.49 & 0.321 & 53.02 & 0.317 \\
\hline Male headed households & 0.935 & 0.006 & 0.935 & 0.006 & 0.936 & 0.006 \\
\hline Years of education of HH & 8.331 & 0.109 & 8.531 & 0.117 & 8.678 & 0.124 \\
\hline Married HH & 0.920 & 0.006 & 0.919 & 0.006 & 0.913 & 0.007 \\
\hline Household size & 6.714 & 0.070 & 7.311 & 0.072 & 8.115 & 0.078 \\
\hline Farmland ownership & 0.746 & 0.011 & 0.737 & 0.011 & 0.781 & 0.010 \\
\hline Farm size (ha) & 3.698 & 0.692 & 2.092 & 0.184 & 1.888 & 0.257 \\
\hline Nonfarm income & 0.507 & 0.012 & 0.611 & 0.011 & 0.373 & 0.011 \\
\hline Monthly food expenditure (丹) & 3277.41 & 63.96 & 3610.5 & 71.10 & 380.89 & 68.47 \\
\hline
\end{tabular}

Table 2: Summary Statistics

Note: Hh Is Household Head

Source: Authors' Computation from Ghs-Panel Surveys 2010/11, 2012/ 2013 and 2015/ 2016

\subsection{Food Security Profile}

As earlier indicated, the food security threshold was pegged at two-thirds of mean per-capital monthly food expenditure implying that households whose per-capita food expenditure is equal to or above the threshold are food secure while those below are food insecure. Based on the above categorization, sampled households were grouped into food secure and food insecure as shown in Table 2 and Figure 1. Table 3 gives the summary of the food security status of household heads in the three waves using deciles. Each decile was computed from taking an average of the per-capita monthly food expenditures of about 183 household heads. Given that two-third ofmean per capita food expenditures are \$2200.6, $\$ 2413.6$ and $\$ 2539.5$ in wave 1, wave2 and wave 3, respectively, household heads from the fifth decile upwards can be said to be food secure of which more than half of the sampled population falls into this category (Figure 1). Household heads represented in the first to fourth decile are considered to be food insecure as their mean per-capita monthly food expenditure was below the food security threshold.

\begin{tabular}{|c|c|c|c|}
\hline Deciles & $\begin{array}{c}\text { Wave 1 } \\
\text { MPCE (N) }\end{array}$ & $\begin{array}{c}\text { Wave 2 } \\
\text { MPCE (N) }\end{array}$ & $\begin{array}{c}\text { Wave 3 } \\
\text { MPCE (N) }\end{array}$ \\
\hline First & 496.98 & 593.37 & 591.93 \\
\hline Second & 964.32 & 1168.83 & 1314.95 \\
\hline Third & 1427.11 & 1602.56 & 1798.66 \\
\hline Fourth & 1875.13 & 2053.86 & 2332.70 \\
\hline Fifth & 2376.78 & 2519.37 & 2894.58 \\
\hline Sixth & 2884.28 & 3137.56 & 3442.54 \\
\hline Seventh & 3482.35 & 3772.19 & 3987.40 \\
\hline Eight & 4287.82 & 4703.72 & 4958.27 \\
\hline Ninth & 5645.49 & 6113.94 & 6291.47 \\
\hline Tenth & 9402.58 & 10493.38 & 10445.66 \\
\hline Total & 3300.87 & 3620.39 & 3809.22 \\
\hline 2/ 3MPCFE & 2200.58 & 2413.59 & 2539.48 \\
\hline
\end{tabular}

Table 3: Households Food Security Distribution

*MPCFE- Mean per Capita Food Expenditure

Source: Authors' Computation from GHS-Panel Surveys 2010/ 11, 2012/ 2013 and 2015/ 2016

Figure 2 shows the trend in food security. This was observed to follow no definite pattern over the years. The percentage of household heads who were food secure was shown to be highest in wave $3(61.73 \%)$ and least in wave 2 (57.8\%). Although there was a plunge in food security status between wave 1 and wave 2, an overall increase was noticed across the waves (59.16\% to 61.7\%). The observed increase in food security can be linked to a number of agricultural programmes introduced by the Federal government of Nigeria during this period. Notable among these programmes is the Agricultural Transformation Agenda launched in 2011 and whose objective was centred on increasing income and livelihood of smallholder farmers and entrepreneur's resident in rural areas. Thus, the increase in the percentage of rural households who were food secure in wave $3(2015 / 2016)$ could be thought of as one of the achievements of the programme whose major objective according to FMARD (2011) was to increase domestic food supply by 20 million metric tonnes by 2015. As at 2011, the ministry of agriculture asserted that s $45 \%$ of its 2015 target has already been met in 2011 (Chimaobi and Chizoba, 2015) 


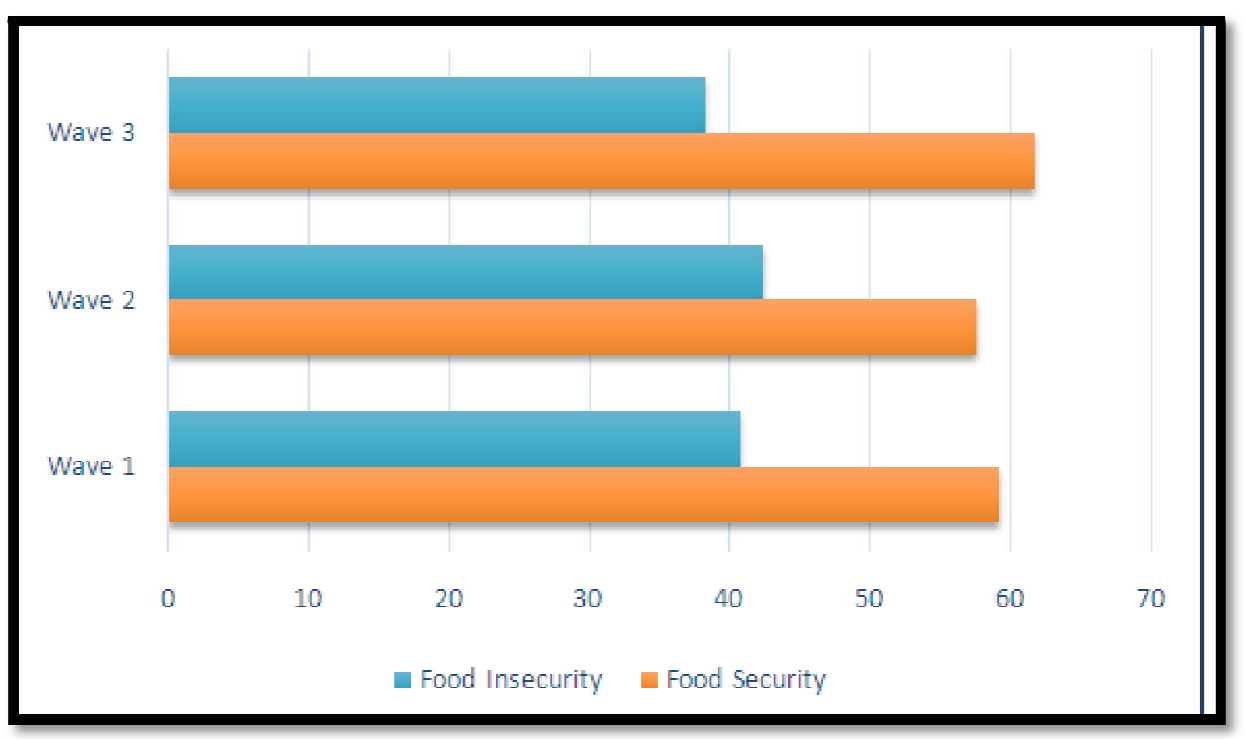

Figure 1: Food Security Transitions by Wave

Source: Authors' Computation from GHS-Panel Surveys 2010/ 11, 2012/ 2013 and 2015/ 2016

\subsection{Markov Chain Analysis of Food Security Transitions}

Studies (Ribar and Hamrick, 2003; Baulch et al., 2003) have revealed that the poverty or food security status of households are not necessarily fixed but may change at different time periods. Accordingly, Tables 2aand $2 \mathrm{~b}$ reveal the transition matrix and the resulting probabilities of transitioning into or out of food security. Results from Table 3 reveal that about $69.6 \%$ and $69.1 \%$ of households who were food secure in 2010 maintained their food security status in 2012 and 2015 respectively while the corresponding figures for those who were food insecure are 59.8\% and $49.0 \%$ respectively. Using 2012 as a reference point, over two-third of the households remained food secure in 2015 while $55.5 \%$ were observed to be food insecure in both periods (Table 5). The overall result in Table 5 shows $57.4 \%$ of the households were found to be chronically food secure (food secure in all the waves) while $55.5 \%$ were always food insecure. Households that exited food security in either 2012 or 2015 were $42.5 \%$ while those who transitioned into food security were put at $66.9 \%$.Invariably,the proportion of households whose food security status improved over the years is more than those whose status deteriorated. Taking the chronic and transitory food security together, it can be said that about $85.1 \%$ of the sampled households were food secure in at least one wave. Although, quite a large percentage of the households were food secure in one wave or the other, what is most important is the number of households transitioning in and out of food security over time (53.5\%) as this represents high level of vulnerability among rural households? This brings to the fore the need to identify the drivers of these transitions as discussed in subsequent sections.

In order to determine the proportion of households that will be food secure in the long run, results on Table 4 were further decomposed and analysed. Results from the transition probability matrix show that in the short run, the probability that a household will be food secure or food insecure are $61.73 \%$ and $38.27 \%$ respectively. In the long run, when the mobility of household into or out of food security is equal, the probability of transitioning into food security is $62.2 \%$ while the probability of exiting the status is $38.27 \%$

\begin{tabular}{|c|c|c|c|c|c|c|c|}
\hline & $\mathbf{2 0 1 2}$ & & & $\mathbf{2 0 1 5}$ & & \\
\hline & Status & $\begin{array}{c}\text { Food } \\
\text { secure }\end{array}$ & $\begin{array}{c}\text { Food } \\
\text { Insecure }\end{array}$ & Total & $\begin{array}{c}\text { Food } \\
\text { Secure }\end{array}$ & $\begin{array}{c}\text { Food } \\
\text { Insecure }\end{array}$ & Total \\
\hline 2010 & Food Secure & $\begin{array}{c}753 \\
(0.696)\end{array}$ & $\begin{array}{c}329 \\
(0.304)\end{array}$ & 1082 & $\begin{array}{c}748 \\
(0.691)\end{array}$ & $\begin{array}{c}334 \\
(0.309)\end{array}$ & 1082 \\
\hline & Food & 300 & 447 & 747 & 381 & 366 & 747 \\
& Insecure & $(0.402)$ & $(0.598)$ & & $(0.510)$ & $(0.490)$ & \\
\hline Total & & 1053 & 776 & & 1129 & 700 & \\
\hline
\end{tabular}

Table 4: Transition Matrix of Food Security Status

Note: Figures in Parenthesis Represent Values for the Transition Probability Matrix Source: Computed from GHS-Panel Surveys, 2010/2011, 2012/ 2013 and 2015/ 2016 


\begin{tabular}{|c|c|c|c|c|}
\hline & & 2012-2015 & & \\
\hline & Status & Food secure & Food Insecure & Total \\
\hline 2010 & Food Secure & $577(0.574)$ & $427(0.425)$ & 1004 \\
\hline & Food Insecure & $552(0.669)$ & $273(0.331)$ & 825 \\
\hline Total & & 1129 & 700 & 1053 \\
\hline 2012 & Food Secure & $784(0.746)$ & $269(0.254)$ & 776 \\
\hline & Food Insecure & $345(0.445)$ & $431(0.555)$ & 1829 \\
\hline Total & & 1129 & 700 & \\
\hline
\end{tabular}

Table 5: Transition Matrix of Food Security Status

Note: The Figures in Bold Represents Values for Transition in Food Security between 2012 and 2015 and Those in Parenthesis Represent Values for the Transition Probability Matrix

Source: Computed from GHS-Panel Surveys, 2010/ 2011,2012/ 2013 and 2015/ 2016

\subsection{Determinants of Household Food Security}

The study used a random effects probit model to analyse the dynamics of food security among rural households between 2010, 2012 and 2015. As shown in table 4, The Chi-square value of 317.1, significant at $p<0.01$, implies that the model has a good fit. The results presented are marginal effects and virtually all the estimated coefficients have the expected signs. Out of the ten (10) explanatory variables, only three did not have significant effect on the probability of being food secure (Sex, age and land ownership). Consistent with the findings of Olayemi (1998) and Adepoju and Adejare (2013), Table 4 reveals that marital status has a positive significant effect $(p<0.01)$ on household food security. A unit increase in the population of married household heads increases the probability of being food secure by $45.5 \%$. This result is plausible given that married individuals have greater tendencies to pool resources together than their unmarried counterparts and hence the observed effect on food security. Surprisingly, household size was shown to increase instead of decrease food security. This result is a deviation from the findings of most studies (Amao \& Ayantoye, 2015; Adepoju and Adejare 2013; Ayantoye et al, 2011) where a negative relationship has been observed. In as much as the authors do not doubt the correctness of the above claim, we believe that a possible explanation for this deviance could be that the sampled households have alternative means of generating income (Table 2) and/ or that the additional household member contributes or will later add to the households total income through involvement in various income generating activities or other childbirth associated benefits. For example, in some cultures in Nigeria especially in rural areas, the birth of a girl child is seen as a blessing asparents of potential suitors bring food items and other giftsthat will be needed by the child until she attains puberty. Also, the large family size can encourage farm expansion (Jerumeh and Omonona, 2018) especiallyin cases where family members are more incentivized working on family plots that participating in other activities.

Years of education and household asset increased the probability of being food secure by $18.3 \%(p<0.01)$ and $58.9 \%(p<0.01)$ respectively. With more years of education, individuals are better positioned to secure high paying jobs which invariably makes expenditure on basic needs less burdensome. Equally, the larger the household assets, the higher the probability of being food secure. These results are in consonance with the findings of Ayantoye et al (2011). Results from Table 4 also shows that at $p<0.01$, households with access to credit or extension are $22.1 \%$ and $43.2 \%$ more likely to be food secure than those without access. Involvement in in off-farm activities was also shown to increase the likelihood of food security among rural households. An additional one unit increase in non-farm activity, increases household food security by $34.0 \%(\mathrm{p}<0.01)$. By implication, agriculture may not necessarily be the only panacea to the problem of food insecurity in Nigeria. This result is further strengthened by the findings of Pitoro and Chagomoka (2017) who found out that off farm activities reduced the propensity of being food insecure.

\begin{tabular}{|c|c|c|}
\hline Variables & Marginal Effects & Standard Error \\
\hline Sex & -0.134 & 0.187 \\
\hline Age & 0.002 & 0.002 \\
\hline Marital Status & $0.455^{* * *}$ & 0.154 \\
\hline Household size & $0.055^{* * *}$ & 0.009 \\
\hline Years of education & $0.183^{* * *}$ & 0.041 \\
\hline Household Asset & $0.589^{* *}$ & 0.069 \\
\hline Access to credit & $0.221^{* * *}$ & 0.054 \\
\hline Non-farm income & $0.340^{* * *}$ & 0.054 \\
\hline Land ownership & 0.014 & 0.062 \\
\hline Access to extension & $0.432^{* * *}$ & 0.071 \\
\hline Observations & 2,762 & \\
Rho & 0.001 & \\
Log likelihood & -1634.722 & \\
Wald chi2 & 317.05 & \\
Prob>chi2 & 0.0000 & \\
\hline
\end{tabular}

Table 6: Random Effects Model Showing the Determinants of Food Security between 2010, 2012 and 2015 *** Denotes Significant at $1 \%$

Source: Computed from GHS-Panel Surveys, 2010/ 2011, 2012/ 2013 and 2015/ 2016 


\subsection{Drivers of Transitions in Food Security Status}

In addition to the panel estimation of the determinants of food security in rural Nigeria, the study also considered the factors influencing the changes in the food security status of the households. More specifically, we focused on the factors affecting the likelihood of households to be "always food secure", "exit food security" or "enter food security". Resultantly, Table 5 presents these three transition categories alongside their major drivers.

In order for households to be self-sufficient and self- sustaining, there is a need to acquire more years of education, increase their asset holdings as well as have access to credit whether formal or informal. Table 5 shows that a unit increase in years of education, asset ownership and access to credit will increase the probability of being food secure by $6.8 \%(p<0.01), 20 \%(p<0.01)$ and $8.1 \%(p<0.01)$ respectively. These results are in consonance with the findings of Ayantoye et al (2011) who identified the above-named factors as important drivers of food security. For possible reasons previously highlighted, an increase in household size increases the probability of always food secure by $2.8 \%$ ( $\mathrm{p} \varangle 0.01$ ). As shown in the Markov chain analysis (Table 3), about one-third of the households transitioned from being food secure to food insecure when comparisons were made across the three waves. Thus, the sex of the household head, marital status and asset ownership have been identified as key determinants of not exiting food security. The higher the proportions of male headed households, the lower the likelihood of households exiting food security. This result is plausible given more representation of males in productive activities than females who have to juggle between their productive and reproductive roles. This rationality is further substantiated given the significant underrepresentation of women in secure wage employment both in private and public sectors as well as earninglower wages than men (UNAIDS, 2012). The significant positive relationship between marital status and exiting food security indicates that the probability of exiting food security increases with the increase in the proportion of married household heads. The result also shows that increasing number of assets owned by households by one unit reduces the probability of exiting food security by $11.2 \%$ $(p<0.01)$. This result is in consonance with the findings of Ayantoye et al (2011).

For those trapped in food insecurity to transition into food security, table 3 reveal four significant factors which are age, years of education, household size and asset ownership. Household heads that are elderly with large household size are less likely to become food secure. Unexpectedly, years of education and asset ownership were observed to have negative relationship with the probability of entering food security. These results may be due to the fact that rural households do not necessarily depend on asset ownership or years of education to be food secure. This is particularly true for years of education which was found to be quite low (Table 2).

\begin{tabular}{|c|c|c|c|}
\hline Variables & \multicolumn{2}{|c|}{$\begin{array}{l}\text { Probability of households ... } \\
\end{array}$} & \\
\hline & Always food secure & Exiting Food security & Entering food security \\
\hline Male headed households & $\begin{array}{c}0.053 \\
(0.116)\end{array}$ & $\begin{array}{c}-0.191 * * \\
(0.102)\end{array}$ & $\begin{array}{c}0.088 \\
(0.088)\end{array}$ \\
\hline Age & $\begin{array}{c}0.002 \\
(0.002)\end{array}$ & $\begin{array}{l}-0.001 \\
(0.001)\end{array}$ & $\begin{array}{l}-0.002^{*} \\
(0.001)\end{array}$ \\
\hline Marital status & $\begin{array}{c}0.003 \\
(0.095) \\
\end{array}$ & $\begin{array}{c}0.180^{*} \\
(0.093)\end{array}$ & $\begin{array}{c}-0.008 \\
(0.071) \\
\end{array}$ \\
\hline Years of education & $\begin{array}{l}0.068 * * * \\
(0.021)\end{array}$ & $\begin{array}{l}-0.004 \\
(0.019)\end{array}$ & $\begin{array}{c}-0.042^{* *} \\
(0.021)\end{array}$ \\
\hline Household size & $\begin{array}{c}0.028^{* * *} \\
(0.005)\end{array}$ & $\begin{array}{c}3.1 \mathrm{E}-4 \\
(0.005)\end{array}$ & $\begin{array}{l}-0.008^{*} \\
(0.005)\end{array}$ \\
\hline Asset & $\begin{array}{c}0.200^{* * * *} \\
(0.035)\end{array}$ & $\begin{array}{c}-0.112^{* * *} \\
(0.040)\end{array}$ & $\begin{array}{c}-0.194^{* * *} \\
(0.051)\end{array}$ \\
\hline Land ownership & $\begin{array}{c}0.09 \\
(0.034)\end{array}$ & $\begin{array}{c}0.024 \\
(0.029)\end{array}$ & $\begin{array}{l}-0.028 \\
(0.028)\end{array}$ \\
\hline Farm size & $\begin{array}{c}-0.001 \\
(0.001)\end{array}$ & $\begin{array}{l}-3.3 \mathrm{E}-4 \\
(0.001)\end{array}$ & $\begin{array}{l}-1.9 \mathrm{E}-4 \\
(4.2 \mathrm{E}-4)\end{array}$ \\
\hline Access to credit & $\begin{array}{c}0.081^{* * *} \\
(0.030)\end{array}$ & $\begin{array}{l}8.8 \mathrm{E}-5 \\
(0.026)\end{array}$ & $\begin{array}{l}-0.015 \\
(0.026)\end{array}$ \\
\hline Observations & 976 & 976 & \\
\hline LR chi2 & 108.93 & 16.40 & 40.77 \\
\hline Prob>chi2 & 0.0000 & 0.0590 & 0.000 \\
\hline Log likelihood & -579.523 & -458.367 & -452.075 \\
\hline Pseudo R2 & 0.086 & 0.018 & $0.0431 \mathrm{x}$ \\
\hline
\end{tabular}

Table 7: Factors Influencing Transition in Food Security among Rural Households in Nigeria $* * *, * *, *$ Denote Significant at $1 \%, 5 \%$ and $10 \%$ Respectively

Source: Computed From GHS-Panel Surveys, 2010/ 2011, 2012/ 2013 and 2015/ 2016

\section{Conclusion and Policy Implication}

The study employed Generalised Household survey (GHS), a country-wide panel data, to investigate trends in the food security status of rural households in Nigeria. More specifically, the research paper considered the main drivers of transitions in food security status. 
From the study, it can be concluded that although majority of the household heads were food secure in 2010 and 2012, almost one half of this population transitioned into food insecurity in 2015. Sex of the household head, marital status and asset ownership were identified as key determinants of mobility into food insecurity. The study also revealed that the relatively high level and fair stability of food security in the sampled area can be linked to household size, marital status, years of education, asset ownership, access to credit or extension and non-farm income.

It is against this backdrop that the study makes the following policy recommendations:

- Low literacy level in the rural areas calls for urgent government intervention as education was shown to significantly influence households' food security status

- Financial services and microcredit programmes as well as multisectoral network of extension services should be provided for rural households in Nigeria. These interventions should however be gender sensitive as male headed households have been shown to have higher tendencies of being food secure than their female counterparts.

- Since involvement in non-farm activities improves food security, policy should not only focus on food production strategies but also on the provision of non-farm employment opportunities especially for those households who recorded high levels of food insecurity.

\section{References}

i. Abdullah, et al. Factors affecting household food security in rural northern hinterland of Pakistan. Journal of the Saudi

Society of Agricultural Sciences (2017), http:/ / dx.doi.org/ 10.1016/j.jssas.2017.05.003

ii. Adepoju and Adejare (2013): Food Insecurity Status of Rural Households during the Post-planting season in Nigeria. Journal of Agriculture and Sustainability, 4(1):16-35.

iii. Amao and Ayatoye (2015): Correlates of Food Insecurity Transition and its Determinants among Farming Households in North Central, Nigeria. Journal of Economics and Sustainable Development, 6(24): 230-244

iv. Ayantoye K, Yusuf S, Omonona B, Amao JO 2011. Food insecurity dynamics and its correlates among rural households in South Western Nigeria. International Journal of Agricultural Economics and Rural Development, 4(1): 43-55

v. Baltagi B.H. (undated). Panel Data Methods*. In Aman Ullah and David E.A, A Paper prepared for the Handbook of Applied Economic Statistics, Giles, Marcel Dekker, New York.

vi. Baulch, B. and N. McCulloch. (1998). Being Poor and Becoming Poor: Poverty Status and PovertyTransitions in Rural Pakistan. Preliminary material and interim research resultscirculated to stimulatediscussion and critical comment. Institute of Development Studies, University of Sussex

vii. CFS (2012): Coming to terms with terminology: Food security, Nutrition security, Food security and Nutrition, Food and nutrition security, Committee on World Food Security (CFS), Thirty-ninth Session, Rome, 15-20 October 2012.

viii. Economic and Social Research Centre (ESRC) (2006). An Overview of Methods for the Analysis of Panel Data. ESRC National Centre for Research Methods Briefing Paper. NCRM/ 007

ix. Federal Ministry of Agriculture and Rural Development (FMARD). Action plan for cassava transformation in Nigeria.

x. Food and Agriculture organization of the United Nations (2010), The state of food insecurity in the world 2009. Online (Available from: http:/ / www.fao.org/ docrep/ 013/i1683e/ i1683e.pdf.)

xi. Food and Agriculture Organization of the United Nations (2011a). The State of Food Insecurity in the World 2011. [Online] Available from: http:// www fao.org/ docrep/ 013/i1683e/i1683e.pdf.

xii. Gazuma EG (2018) An Empirical Examination of the Determinants of Food Insecurity among Rural Farm Households: Evidence from Kindo Didaye District of Southern Ethiopia. Bus Eco J 9: 345. doi: 10.4172/ 21516219.1000345

xiii. Gibbons, R. D., \& Bock, R. D. (1987). Trend in correlated proportions. Psychometrika, 52, 113-124

xiv. Greene, W. H. (2003). Econometric Analysis, Prentice Hall, Upper Saddle River.

xv. Greene W.H. (2010). Econometric Analysis (7th ed.). Upper Saddle River, NJ: Prentice Hall

xvi. Gross, R. Schultink, W., \& Kielmann, A.A. (1998), Community nutrition: definition and approaches: In Sadler, M., Strain, J. J, Caballero, B. (Eds.), Encyclopedia of Human Nutrition, 433-441.London: Academic Press Ltd.

xvii. Gujarati, D.N. (2003). Basic Econometrics, International Edition-4thed. McGraw-Hill Higher Education.pp. 25-31. ISBN 0-07-112342-3.

xviii. Jerumeh, T. R., \& Omonona, B. T., Determinants of transition in farm size among cassava-basedfarmers in Nigeria, Kasetsart Journal of Social Sciences (2018), https:/ / doi.org/ 10.1016/j.kjss.2018.02.008

xix. Junge B., Abaidoo, R., Chikoye D., Alabi T., and Stahr, K. (2006). Monitoring of Land Use Intensification and Linkage to Soil Erosion in Nigeria and Benin. Conference on International Agricultural Research for Development. Tropentag 2006, University of Bonn, October 11-13, 2006.

xx. London, S. and E. Scott, (2005). Food Security, Stability and Change among Low-Income Urban Women. USDA Economic Research Service.

xxi. Olayemi J.K. (1998): „Food Security in Nigeria“. Research Report No. 2. Development Policy Centre, Ibadan, Nigeria.

xxii. Omonona B.T. and Agoi G.A. (2007): An Analysis of Food Security Situation among Nigerian urban Households: Evidence from Lagos State Nigeria. Journal of Central European Agriculture, 8 (3): 397-406. 
xxiii. Pitoro P. and T. Chagomoka (2017). Food Security Dynamics and its Drivers in Rural Mozambique. International Journal of Sciences. 6(5): 55-65

xxiv. Ribar, D.C, and K.S. Hamrick. (2003). Dynamics of Poverty and Food Insufficiency: Food Assistance and Nutrition Research Report No. 36 FANRR Washington, DC: USDA

xxv. StataCorp. 2015. Stata: Release 14. Statistical Software. College Station, TX: StataCorp LP.

xxvi. Torero, M. (2014). Food Security Brings Economic Growth - Not the Other Way Around. Accessed at http:// www.ifpri.org/blog/food-security-brings-economic-growth-not-other-way-around 1/ 7 on 16 November 2017.

xxvii. USAID (2014) New Alliance for Food Security and Nutrition: Annual Progress Review (2013-2014) Report.

xxviii. Vaisey S. and Miles A. (2014). What you can- and Can't Do with Three-Wave Panel Data. Sociological Methods and Research online:1-24

xxix. World Bank (2001): Poverty and Hunger: Issues and Options for Food Security in Developing Countries. Washington, DC, USA: World Bank

xxx. World Bank (2016): "World Development Indicators." URL: http:// data.worldbank.org/ data-catalog/worlddevelopment-indicators.

xxxi. World Bank, (2007). World Development Report 2008: Agriculture for Development. Washington, D.C: World Bank.

xxxii. World development Indicator WDI (2015). Retrieved from www.knoema.com 